\title{
Spatial neglect
}

OPEN ACCESS

${ }^{1}$ Centre for Restorative Neuroscience, Division of Brain Sciences, Imperial College London, London, UK ${ }^{2}$ Department of Neurology, University Hospital Coventry, Coventry, West Midlands, UK

\section{Correspondence to}

Dr Paresh Malhotra, Centre for Restorative Neuroscience, Division of Brain Sciences, Imperial College London, Charing Cross Campus, Fulham Palace Road, London W6 8RF, UK; p.malhotra@imperial.ac.uk

Accepted 15 April 2015 Published Online First 28 May 2015

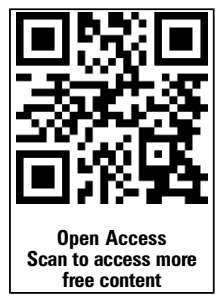

CrossMark

\author{
To cite: Li K, Malhotra PA. \\ Pract Neurol 2015;15: \\ 333-339.
}

\author{
Korina $\mathrm{Li}^{1,2}$ Paresh A Malhotra ${ }^{1}$
}

\begin{abstract}
The syndrome of visuospatial neglect is a common consequence of unilateral brain injury. It is most often associated with stroke and is more severe and persistent following right hemisphere damage, with reported frequencies in the acute stage of up to $80 \%$. Neglect is primarily a disorder of attention whereby patients characteristically fail to orientate, to report or to respond to stimuli located on the contralesional side. Neglect is usually caused by large strokes in the middle cerebral artery territory and is heterogeneous, such that most patients do not manifest every feature of the syndrome.

A number of treatments may improve neglect, but there is no widely accepted universal approach to therapy. Although most patients recover spontaneously, the evidence suggests that they continue to have significant cognitive impairments, particularly relating to attention.
\end{abstract}

\section{INTRODUCTION}

The syndrome of spatial neglect is relatively common. Several pathological processes may cause it, including neurodegenerative disease, ${ }^{1}{ }^{2}$ neoplasia ${ }^{3}$ and trauma, ${ }^{4}$ although it is most common in the context of hemispheric stroke. ${ }^{5}$ Because of its implications for the understanding of the perception and representation of space, neglect has been of considerable interest to neuroscientists, psychologists and philosophers. ${ }^{6-8}$ However, it is also very important to clinicians as it may profoundly affect recovery from stroke; indeed, neglect's negative effects on rehabilitation outcome may be even greater than those of hemiplegia. ${ }^{9} 10$ Neglect may follow right hemisphere stroke in up to $82 \%$ of patients ${ }^{5}$ in the acute stage, but most studies describe rates closer to $50 \% .^{11}$

The terms unilateral neglect, hemineglect and spatial neglect are used interchangeably. They are generally defined as an inability to perceive, report and orient to sensory events towards one side of space, contralateral to the side of the lesion, with or without a primary sensory deficit. ${ }^{12}$ Neglect is more common and longer-lasting after right hemisphere stroke, most likely because of the right hemisphere's key role in attentional processes; thus, most of the discussion below refers to neglect for the left side of space. ${ }^{13}$

\section{NEGLECT AND EXTINCTION}

Neglect should be distinguished from the related phenomenon of sensory extinction (sometimes termed visual or sensory inattention). This refers to a failure to report a contralesional stimulus only in the presence of a competing ipsilesional stimulus, when both stimuli are briefly simultaneously presented ${ }^{2}$ (figure 1). Neglect and extinction often coexist but can also sometimes dissociate from each other, and patients can sometimes continue to show visual extinction after their neglect has recovered. Note that neglect and extinction do not obey the vertical meridian in the way that hemianopia or quadrantanopia do, but rather represent a gradient across space. Thus, patients can still neglect or extinguish items that are relatively contralesional, even if they are still within the ipsilesional half of space (see figure 2 and video link below). ${ }^{14}$ With severe neglect, it may be very difficult to detect hemianopia; in our experience, in these circumstances careful clinical examination by confrontation, sometimes using visual threat, helps more than automated methods.

\section{THE 'TYPICAL' PATIENT}

Although there are several standard tests for neglect (see below), people with moderate to severe neglect show a number of behaviours that are often clearly visible to relatives as well as clinical staff. The most severely affected patients direct their gaze towards the side of the lesion, to the point where they will not fixate on the person speaking to them. In addition, they may eat food only from one side of their plate, or pay less attention to one side when grooming, such that they 


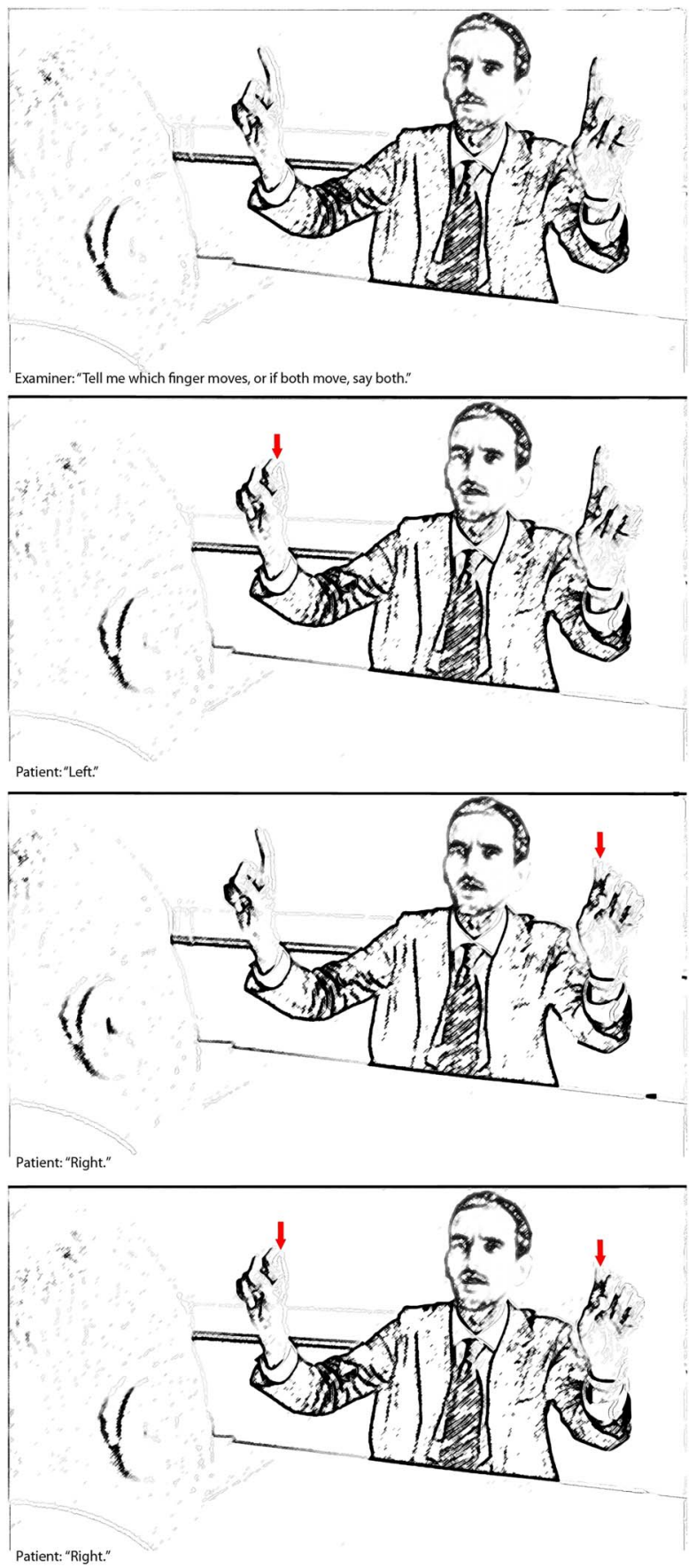

Figure 1 Demonstration of visual extinction. The patient can report the left-sided (middle panel) stimulus and the right-sided stimulus (top panel) when they are presented on their own, but reports only the rightward stimulus when both are presented together (bottom panel). Note that in the video examination the patient manifests left-sided extinction as well as a left-sided hemianopia.

shave, or apply make up to, only one side of their face (sometimes referred to as personal neglect). Neglect may also be very apparent to therapists during rehabilitation. For instance, a wheelchair user may repeatedly bump into walls and objects on the neglected side, or may omit words when reading text on the one side of the page, or misread one side of

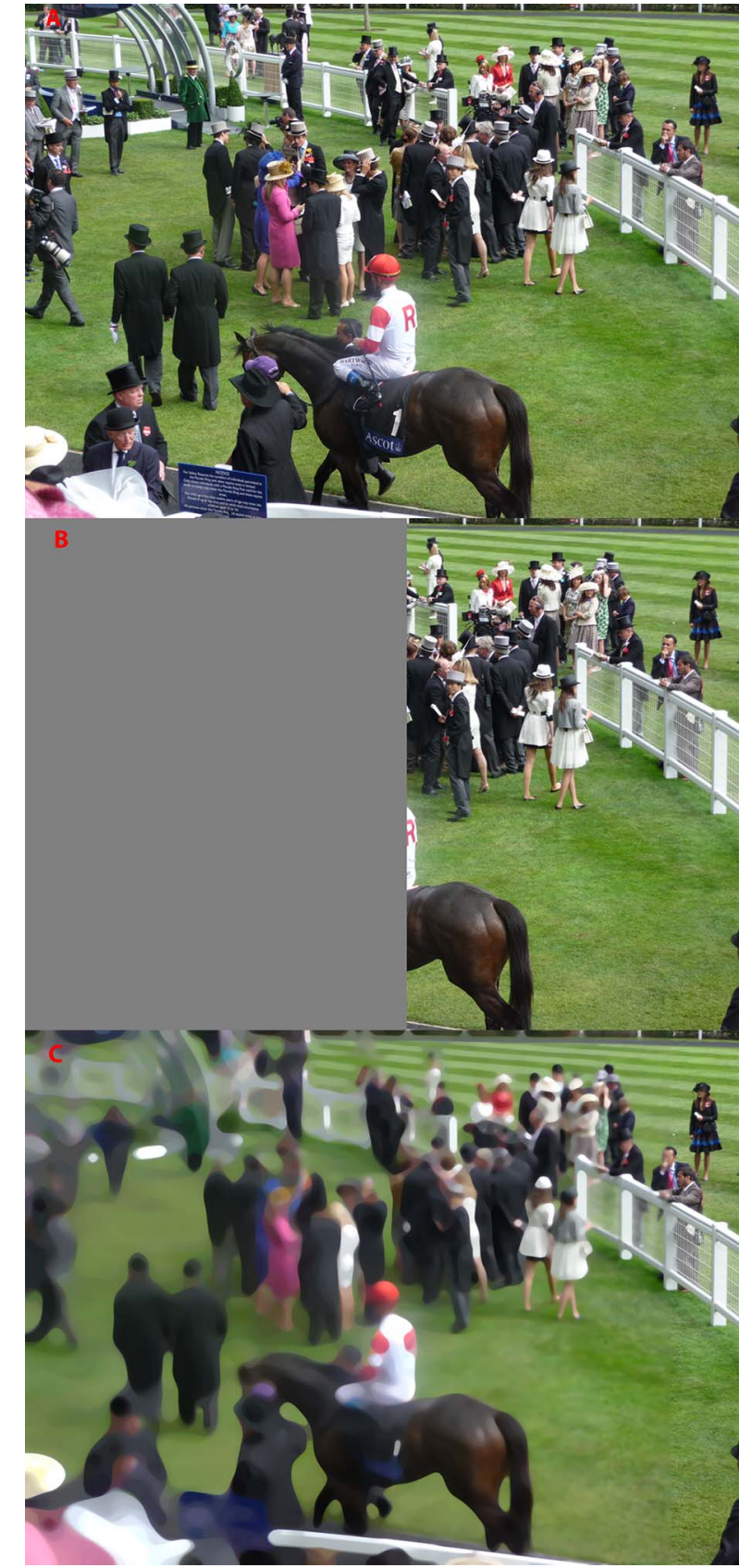

Figure 2 Schematic representation of how a visual scene might appear to people with left homonymous hemianopia (middle panel) and left neglect (bottom panel). Whereas hemianopia obeys the midline and affects only the contralesional visual field, neglect affects parts of the ipsilesional field in addition to the contralesional field, such that there is a lateralised bias of attention towards the side of the lesion.

individual words (neglect dyslexia). Some patients tend not to use their contralesional limb even when there is no weakness or sensory loss: this is termed motor neglect (see table 1 for further related deficits). For descriptions from two patients and their relatives, see http://www.theguardian.com/science/video/2012/dec/ 23/stroke-half-world-disappear-video (also available at https://www.youtube.com/watch?v=d4FhZs-m7hA). 
Table 1 Related impairments

\begin{tabular}{ll} 
Anosognosia & $\begin{array}{l}\text { Unawareness of a specific deficit. Patients may be } \\
\text { unaware of neglect and also unaware of } \\
\text { hemiplegia. }\end{array}$ \\
Somatoparaphrenia & $\begin{array}{l}\text { A delusional belief relating to the contralesional } \\
\text { limbs or side of the body, such that a patient does } \\
\text { not believe that the limb/side belongs to them. }\end{array}$ \\
Allochiria & $\begin{array}{l}\text { A patient responds to a stimulus to one side of the } \\
\text { body as if it had been to the other side. It can } \\
\text { also be present in drawings where items from the } \\
\text { contralesional side are transposed to the } \\
\text { ipsilesional side. } \\
\text { The inability to draw or copy complex diagrams. } \\
\text { This is often associated with right hemisphere } \\
\text { apraxia }\end{array} \quad \begin{array}{l}\text { damage and persists after rightward bias has } \\
\text { resolved. It is not related to motor apraxia. }\end{array}$ \\
\hline
\end{tabular}

\section{TESTS FOR NEGLECT}

Traditionally, clinicians employ pen-and-paper tasks for their ease of use. These include cancellation tests (eg, see figure 3), line bisection as well as copying (figure 4) and drawing objects. Cancellation tests are most frequently used and are singly more sensitive at detecting visuospatial neglect. ${ }^{15}$ These require subjects to find targets (sometimes embedded amongst distractors) on a centrally placed sheet of paper: patients with neglect tend to start at the ipsilesional edge of the page, often failing to cancel the more contralesional targets altogether. Note that denser arrays with more distractors may reveal a greater degree of neglect, although they are sometimes more difficult for a patient to do. ${ }^{16}$

Line bisection tasks involve marking the midpoint of one or more horizontal lines; patients with left neglect tend to err towards the right of the true centre. More complex figures may be copied or drawn from memory, with subsequent contralesional omissions or distortions of details. ${ }^{17}$

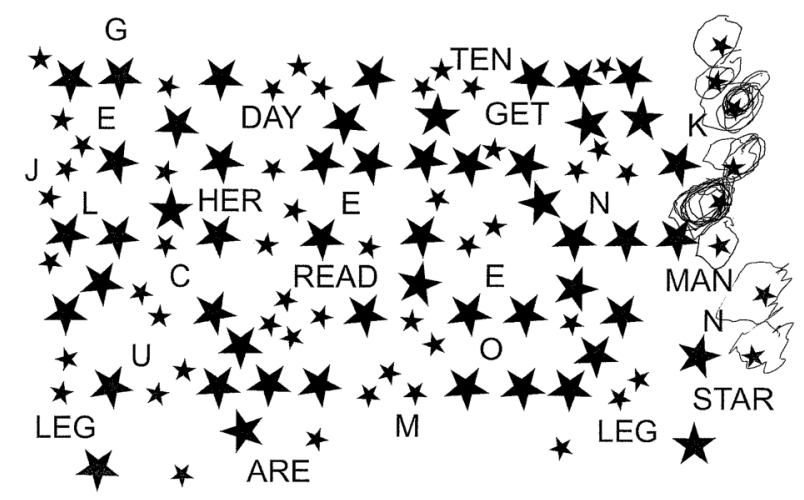

Figure 3 Star cancellation task from the behavioural inattention test. ${ }^{27}$ Patients are asked to find and mark all the small stars without marking the large stars or letters. Patients with severe neglect find targets only at the ipsilesional side of the array, even when they have unlimited time to complete the task. Patients with less severe neglect still tend to start on the right side of the array but may miss only a small number of contralesional targets.

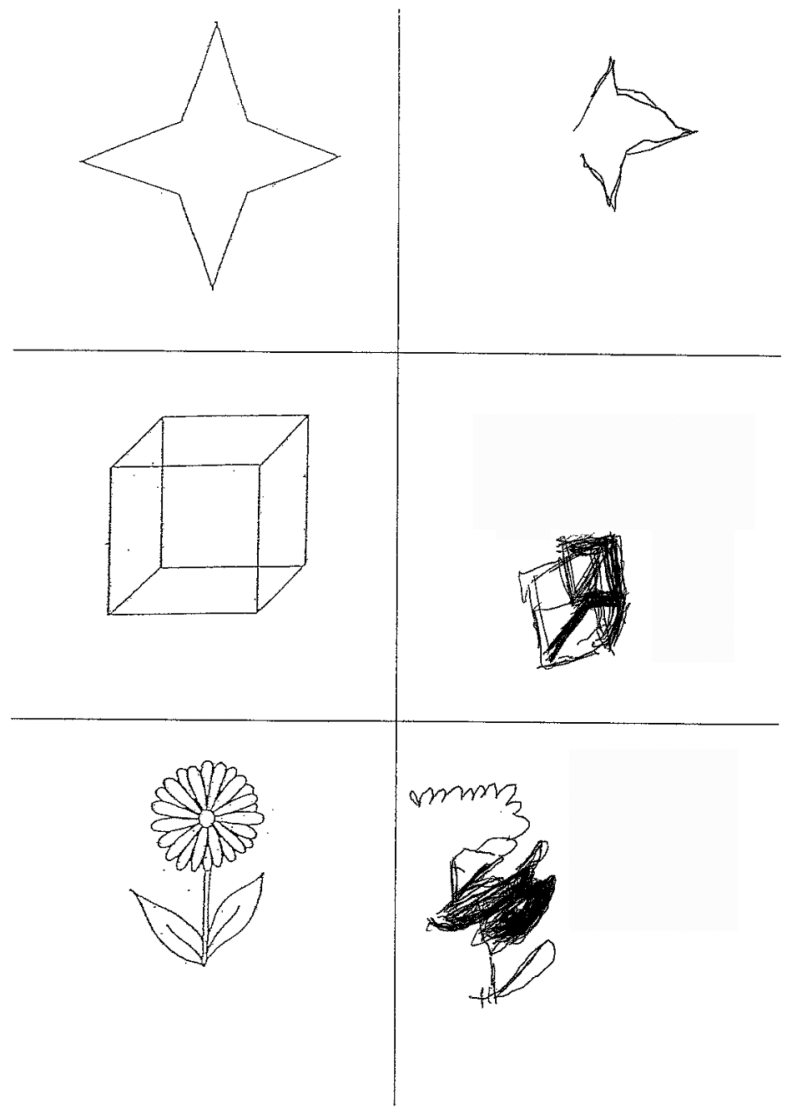

Figure 4 Copying task from the behavioural inattention test. ${ }^{27}$ The patient tends to omit the left-sided elements of each object.

In addition to these pen-and-paper tasks testing for neglect in peripersonal space, there are several tests that tap into the different types of neglect behaviour. For example, personal neglect can be assessed through ecological tests where patients are asked to mime combing their hair or other grooming activities. ${ }^{18}$ Asking people to name items in the room around them tests for neglect in far extrapersonal space: patients with neglect often ignore objects on the left side. ${ }^{19}$ Patients can even be examined for representational neglect by asking them about landmarks in a familiar place (eg, the main square in their home town) and noting whether they omit items on the left side of a remembered scene or mental image. ${ }^{20} 21$

Interestingly, an individual patient's degree of neglect can fluctuate strikingly, ${ }^{22}{ }^{23}$ even within the same day. ${ }^{24}$ This depends upon factors such as overall arousal, which is known to be affected by right hemisphere stroke. ${ }^{13}$ In addition, although many people show neglect on more than one type of task, some groups of patients show dissociations, demonstrating a lateralised bias on only one test and normal performance on others ${ }^{15}{ }^{25}$; even these characteristics may vary over time. ${ }^{26} \mathrm{~A}$ battery of tests is therefore more sensitive to the presence of neglect than is one single task. ${ }^{27-29}$ This variability probably reflects the underlying heterogeneity of each individual's cognitive 
deficits. ${ }^{30}$ Although the core deficit in neglect clearly involves a spatial bias towards ipsilesional space and away from contralesional space, most patients also have several other deficits, some of which are not spatially lateralised but may still contribute to the clinical severity of the syndrome. ${ }^{71}$ This, in turn, reflects the underlying neuroanatomy, as discussed below.

A large proportion of patients recover spontaneously, in that their performance on standard tasks improves. ${ }^{32}$ However, this may be partially secondary to compensatory strategies during formal neuropsychological testing, which do not carry over into activities of everyday living. ${ }^{33}$ In fact, a growing body of evidence suggests that patients who have apparently recovered may still show impairments of attention when tested with more sophisticated tasks. ${ }^{34} 35$

\section{THE ANATOMY OF NEGLECT}

Neglect most frequently follows right cerebral hemisphere damage, as a consequence of middle cerebral artery territory stroke. Although the syndrome is traditionally most closely associated with parietal lesions, ${ }^{36}$ most middle cerebral artery strokes affect several regions and many patients show varying combinations of parietal, temporal and frontal damage. ${ }^{37}$ In addition, neglect can follow subcortical stroke, although this may relate to hypoperfusion and dysfunction of overlying cortical areas. ${ }^{38} 39$

There has been a great deal of controversy concerning the precise anatomy of neglect. ${ }^{40}$ This partly relates to the different imaging methods and time points at which patients have been tested and/or scanned. ${ }^{41}{ }^{42}$ Moreover, many of the divergent findings probably follow from the fact that neglect is a heterogeneous syndrome, and that research groups have used different tests to diagnose the presence of neglect. ${ }^{43}$ In fact, several studies suggest that impairments on different types of task more likely localise to different regions. ${ }^{3744} 45$ Moreover, neglect results from damage to networks of regions involved in attention (see figure 5), and recent work has shown that it can result from damage to white matter tracts, particularly the superior longitudinal fasciculus, as well as individual cortical and subcortical regions. ${ }^{46}{ }^{47}$ At a functional level, the evidence suggests that there is an interhemispheric imbalance in patients with neglect, such that the left hemisphere is relatively overactive after a right hemisphere stroke, causing attention and eye movements to be biased rightwards. ${ }^{48} 49$

The right frontal and parietal regions involved in spatial functions-including the deployment of attention-are also involved in several non-spatial processes such as vigilance and the ability to maintain performance on a task over an extended period of time. ${ }^{50}$ Thus, these non-spatial impairments often accompany, and potentially exacerbate, the key spatial features of neglect ${ }^{31}{ }^{51}$ (see box 1). The right hemisphere lateralisation of these cognitive domains also explains the increased severity and endurance of left

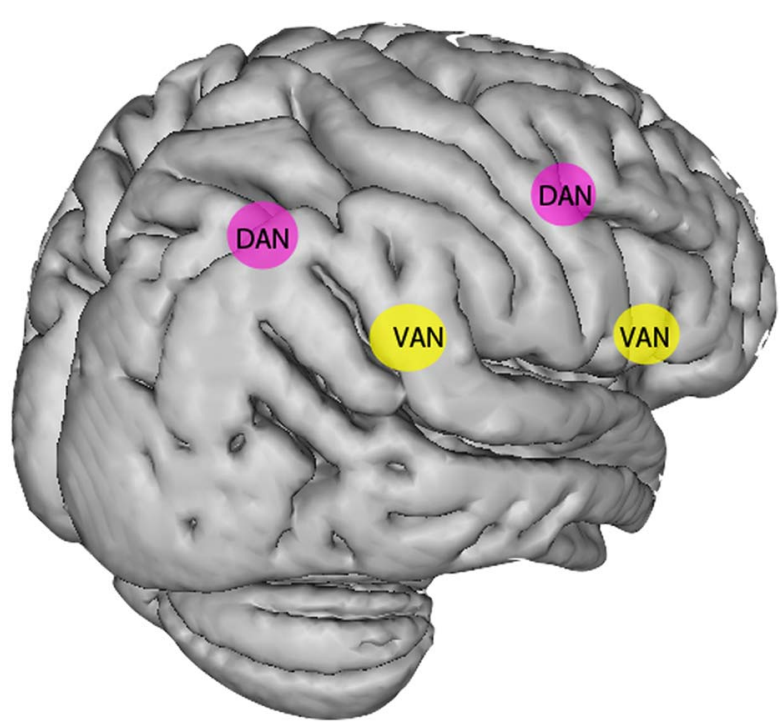

Figure 5 Disruption of attention networks in patients with spatial neglect. The dorsal attention network (DAN, in pink), critical to deploying spatial attention, includes the frontal eye fields anteriorly and the intraparietal sulcus posteriorly. The ventral attention network (VAN, in yellow), which is right-lateralised, includes the inferior frontal gyrus anteriorly and the temporoparietal junction posteriorly. The VAN is involved in sustained attention and arousal, as well as the reorienting of attention. Current accounts of the pathophysiology of neglect suggest that both these networks are disrupted in neglect, with the ventral network (including white matter connections) frequently being structurally damaged by a middle cerebral artery territory stroke, and the dorsal network often remaining structurally intact but showing disrupted function. ${ }^{7}$

neglect compared to right neglect. That is, right-sided strokes lead to several non-spatially lateralised cognitive deficits that exacerbate the effects of spatial bias as well as prolonging recovery. ${ }^{7} 31$

\section{TREATMENT OF NEGLECT}

Although different approaches have been tried in neglect, including behavioural and pharmacological therapies, there is still no clear consensus as to which are most effective and which patients are most likely to respond. ${ }^{52}{ }^{53}$ One particular difficulty in treating this population is that many patients show anosognosia for neglect (see table 1) and hence are unaware of their deficit. This unawareness negatively impacts upon their final outcome. ${ }^{54}$

\section{Box 1 Cognitive deficits in spatial neglect}

Core deficit

- Attentional bias towards the side of the lesion

- Contributory deficits

- Arousal and vigilance

- Visuospatial working memory

- Capacity of attention resources 
The main approach, repeatedly pursued in the treatment and rehabilitation of neglect, involves directly addressing the core deficit of neglect and attempting to reorient attention towards the neglected side. Visual scanning therapy is widely used in rehabilitating patients with neglect. It mainly involves encouraging them to explore the left side of space, often with the help of visual cues. ${ }^{55}$ However, there is little persuasive evidence that it has significant long-term effects. $^{33}$

Vestibular stimulation via caloric irrigation or galvanic stimulation may successfully reorient attention and transiently reduce personal, extrapersonal and even representational neglect. ${ }^{5657}$ Tactile vibration of the left side of the neck has similar effects and may be most effective when combined with other techniques. ${ }^{58}$ In addition, limb activation through passive and active movements of the neglected limb may sometimes help. ${ }^{59}$

One technique that appears to give longer-lasting changes in neglect involves optical prisms. ${ }^{60}$ Patients with left neglect initially wear prisms that displace the visual scene rightward, causing them to misreach to the right of a target. After repeated pointing, and once they have adapted such that they reach accurately, the prisms are removed, leaving patients with a leftward pointing error. Such prism adaptation therapy considerably benefits multiple aspects of neglect. ${ }^{61}$ Although prism adaptation seems to be among the most promising treatments of the last two decades, the evidence from randomised controlled trials is equivocal. It may be that appropriate patient selection is key to effective intervention. ${ }^{62-65}$

A more recent treatment involves brain stimulation techniques. Several studies have suggested that the core deficit in neglect relates to asymmetrical activation of each cerebral hemisphere, such that the lesioned hemisphere is underactive compared with the intact side, with a subsequent imbalanced deployment of spatial attention. ${ }^{66}$ Thus, this asymmetry could be successfully treated either by activating the lesioned hemisphere or inhibiting the overactive contralesioned hemisphere. Early studies with transcranial magnetic stimulation, delivered as theta burst stimulation to inhibit the left hemisphere, suggest that it can accelerate recovery of left neglect ${ }^{67}$ and reduce disability with respect to activities of daily living. ${ }^{68}$

A very different approach to the treatment of neglect aims to improve the contributing cognitive deficits that are not directly related to spatial bias. This can be achieved through non-pharmacological means, such as using alerting tones to boost arousal. ${ }^{69}$ It has also been attempted with a noradrenergic agent, guanfacine, which improved visual search in neglect patients without frontal damage. ${ }^{70}$ Several investigators have also studied dopaminergic therapies since dopaminergic pathway lesions can induce neglect-like behaviour in animal experiments. ${ }^{71} 72$ Although these studies gave conflicting results, ${ }^{73} 74$ the most recent trial involving 16 patients showed that rotigotine, a dopamine agonist, improved cancellation task performance as well as boosting selective attention. ${ }^{75}$

A less obvious line of research has aimed to improve neglect by enhancing motivation. ${ }^{76}$ Anecdotally, task performance has been shown to improve with the incorporation of a monetary goal ${ }^{77}$ and standard contemporary therapy also involves clearly-defined goals. However, there are now empirical studies showing improvement of neglect using motivational and rewarding stimuli in different forms, including anticipated monetary gain, ${ }^{78}$ altering task instruction, ${ }^{79}$ passively listening to pleasant music ${ }^{80}$ and playing a musical sequence. ${ }^{81}$ Although these probably exert their effects via multiple mechanisms, reward processing and music listening have been repeatedly linked to dopaminergic systems, ${ }^{82}{ }^{83}$ and dopamine may play a crucial role in motivational interventions.

\section{CONCLUSIONS}

A key theme running through this review is the syndromic nature of neglect and its underlying heterogeneity. Given this, no one therapeutic approach will be appropriate for all patients, and a key aim for future work will be the careful delineation of cognitive deficits and their individual responsiveness to specific treatments. One further important consideration relates to our understanding of recovery from neglect. It is critical to determine whether residual deficits following apparent recovery on standard tests relate to ongoing symptoms, and how much they impact on activities of daily living.

Twitter Follow P Malhotra at @PareshMalhotra

Contributors KL wrote the first draft or the article. PAM revised the article and both are responsible for the final version.

Funding PAM is funded by a HEFCE Clinical Senior Lectureship, and both authors have received support from the National Institute for Health Research (NIHR) Imperial Biomedical Research Centre.

Competing interests None declared.

Provenance and peer review Commissioned; externally peer reviewed. This paper was reviewed by Masud Husain, Oxford, UK.

Open Access This is an Open Access article distributed in accordance with the terms of the Creative Commons Attribution (CC BY 4.0) license, which permits others to distribute, remix, adapt and build upon this work, for commercial use, provided the original work is properly cited. See: http://creativecommons.org/licenses/by/4.0/

\section{REFERENCES}

1 Andrade K, Samri D, Sarazin M, et al. Visual neglect in posterior cortical atrophy. BMC Neurol 2010;10:68.

2 Bender MB. Disorders in perception, with particular reference to the phenomena of extinction and displacement. Springfield, Ill: Thomas, 1952. 
3 Jackson JH. Case of large cerebral tumour without optic neuritis and left hemiplegia and imperception. $R$ Lond Ophthal Hosp Rep 1876;8:434.

4 La Pointe LL, Culton GL. Visual-spatial neglect subsequent to brain injury. J Speech Hear Disord 1969;34:82-6.

5 Stone SP, Halligan PW, Greenwood RJ. The incidence of neglect phenomena and related disorders in patients with an acute right or left hemisphere stroke. Age Ageing 1993;22:46-52.

6 Churchland PS. Neurophilosophy: toward a unified science of the mind-brain. Cambridge, Mass: MIT Press, 1986.

7 Corbetta M, Shulman GL. Spatial neglect and attention networks. Annu Rev Neurosci 2011;34:569-99.

8 Driver J, Mattingley JB. Parietal neglect and visual awareness. Nat Neurosci 1998;1:17-22.

9 Jehkonen M, Ahonen JP, Dastidar P, et al. Visual neglect as a predictor of functional outcome one year after stroke. Acta Neurol Scand 2000;101:195-201.

10 Denes G, Semenza C, Stoppa E, et al. Unilateral spatial neglect and recovery from hemiplegia: a follow-up study. Brain 1982;105:543-52.

11 Buxbaum LJ, Ferraro MK, Veramonti T, et al. Hemispatial neglect: Subtypes, neuroanatomy, and disability. Neurology 2004;62:749-56.

12 Heilman KM, Watson RT, Valenstein E. Neglect and related disorders. In: Heilman KM, Valenstein E, eds. Clinical neuropsychology. 3rd edn. Oxford: Oxford University Press, 1993:279-336.

13 Mesulam MM. A cortical network for directed attention and unilateral neglect. Ann Neurol 1981;10:309-25.

14 De Renzi E, Gentilini M, Faglioni P, et al. Attentional shift towards the rightmost stimuli in patients with left visual neglect. Cortex 1989;25:231-7.

15 Ferber S, Karnath HO. How to assess spatial neglect--line bisection or cancellation tasks? J Clin Exp Neuropsychol 2001;23:599-607.

16 Kaplan RF, Verfaellie M, Meadows ME, et al. Changing attentional demands in left hemispatial neglect. Arch Neurol 1991;48:1263-6.

17 Gainotti G, Messerli P, Tissot R. Qualitative analysis of unilateral spatial neglect in relation to laterality of cerebral lesions. J Neurol Neurosurg Psychiatry 1972;35: 545-50.

18 McIntosh RD, Brodie EE, Beschin N, et al. Improving the clinical diagnosis of personal neglect: a reformulated comb and razor test. Cortex 2000;36:289-92.

19 Stone SP, Wilson B, Wroot A, et al. The assessment of visuo-spatial neglect after acute stroke. J Neurol Neurosurg Psychiatry 1991;54:345-50.

20 Bartolomeo P, D'Erme P, Gainotti G. The relationship between visuospatial and representational neglect. Neurology 1994;44:1710-14.

21 Bisiach E, Luzzatti C. Unilateral neglect of representational space. Cortex 1978;14:129-33.

22 Machner B, Mah YH, Gorgoraptis N, et al. How reliable is repeated testing for hemispatial neglect? Implications for clinical follow-up and treatment trials. J Neurol Neurosurg Psychiatry 2012;83:1032-4.

23 Jehkonen M, Laihosalo M, Koivisto AM, et al. Fluctuation in spontaneous recovery of left visual neglect: a 1-year follow-up. Eur Neurol 2007;58:210-14.

24 Bailey MJ, Riddoch MJ, Crome P. Treatment of visual neglect in elderly patients with stroke: a single-subject series using either a scanning and cueing strategy or a left-limb activation strategy. Phys Ther 2002;82:782-97.

25 Halligan PW, Marshall JC, Wade DT. Visuospatial neglect: underlying factors and test sensitivity. Lancet 1989; 2:908-11.

26 Hamilton RH, Coslett HB, Buxbaum LJ, et al. Inconsistency of performance on neglect subtype tests following acute right hemisphere stroke. J Int Neuropsychol Soc 2008;14:23-32.

27 Wilson B, Cockburn J, Halligan PW. Behavioural inattention test. Bury St. Edmunds: Thames Valley, 1987.

28 Azouvi P, Bartolomeo P, Beis JM, et al. A battery of tests for the quantitative assessment of unilateral neglect. Restor Neurol Neurosci 2006;24:273-85.

29 Lindell AB, Jalas MJ, Tenovuo O, et al. Clinical assessment of hemispatial neglect: evaluation of different measures and dimensions. Clin Neuropsychol 2007;21:479-97.

30 Bartolomeo P. Visual neglect. Curr Opin Neurol 2007;20: 381-6.

31 Husain M, Rorden C. Non-spatially lateralized mechanisms in hemispatial neglect. Nat Rev Neurosci 2003;4:26-36.

32 Ringman JM, Saver JL, Woolson RF, et al. Frequency, risk factors, anatomy, and course of unilateral neglect in an acute stroke cohort. Neurology 2004;63:468-74.

33 Robertson IH, Halligan PW. Spatial neglect: a clinical handbook for diagnosis and treatment. Hove: Psychology Press, 1999.

34 Russell C, Malhotra P, Deidda C, et al. Dynamic attentional modulation of vision across space and time after right hemisphere stroke and in ageing. Cortex 2013;49:1874-83.

35 Bonato M, Priftis K, Umilta C, et al. Computer-based attention-demanding testing unveils severe neglect in apparently intact patients. Behav Neurol 2013;26:179-81.

36 Mort DJ, Malhotra P, Mannan SK, et al. The anatomy of visual neglect. Brain 2003;126(Pt 9):1986-97.

37 Verdon V, Schwartz S, Lovblad KO, et al. Neuroanatomy of hemispatial neglect and its functional components: a study using voxel-based lesion-symptom mapping. Brain 2010; 133(Pt 3):880-94.

38 Fruhmann Berger M, Johannsen L, Karnath HO. Subcortical neglect is not always a transient phenomenon: evidence from a 1-year follow-up study. J Clin Exp Neuropsychol 2009;31:617-23.

39 Hillis AE, Wityk RJ, Barker PB, et al. Subcortical aphasia and neglect in acute stroke: the role of cortical hypoperfusion. Brain 2002;125(Pt 5):1094-104.

40 Karnath HO, Rorden C. The anatomy of spatial neglect. Neuropsychologia 2012;50:1010-17.

41 Karnath HO, Rennig J, Johannsen L, et al. The anatomy underlying acute versus chronic spatial neglect: a longitudinal study. Brain 2011;134(Pt 3):903-12.

42 Golay L, Schnider A, Ptak R. Cortical and subcortical anatomy of chronic spatial neglect following vascular damage. Behav Brain Funct 2008;4:43.

43 Saj A, Verdon V, Vocat R, et al. 'The anatomy underlying acute versus chronic spatial neglect' also depends on clinical tests. Brain 2012;135(Pt 2):e207; author reply e08.

44 Medina J, Kannan V, Pawlak MA, et al. Neural substrates of visuospatial processing in distinct reference frames: evidence from unilateral spatial neglect. J Cogn Neurosci 2009;21:2073-84.

45 Rorden C, Fruhmann Berger M, Karnath HO. Disturbed line bisection is associated with posterior brain lesions. Brain Res 2006;1080:17-25. 
46 Lunven M, Thiebaut De Schotten M, Bourlon C, et al. White matter lesional predictors of chronic visual neglect: a longitudinal study. Brain 2015;138(Pt 3):746-60.

47 Bartolomeo P, Thiebaut de Schotten M, Doricchi F. Left unilateral neglect as a disconnection syndrome. Cereb Cortex 2007;17:2479-90.

48 Kinsbourne M. A model for the mechanism of unilateral neglect of space. Trans Am Neurol Assoc 1970;95:143-6.

49 Corbetta M, Kincade MJ, Lewis C, et al. Neural basis and recovery of spatial attention deficits in spatial neglect. Nat Neurosci 2005;8:1603-10.

50 Posner MI, Petersen SE. The attention system of the human brain. Annu Rev Neurosci 1990;13:25-42.

51 Robertson IH, Manly T, Beschin N, et al. Auditory sustained attention is a marker of unilateral spatial neglect. Neuropsychologia 1997;35:1527-32.

52 Riestra AR, Barrett AM. Rehabilitation of spatial neglect. Handb Clin Neurol 2013;110:347-55.

53 Bowen A, Hazelton C, Pollock A, et al. Cognitive rehabilitation for spatial neglect following stroke. Cochrane Database Syst Rev 2013;7:CD003586.

54 Gialanella B, Monguzzi V, Santoro R, et al. Functional recovery after hemiplegia in patients with neglect: the rehabilitative role of anosognosia. Stroke 2005;36:2687-90.

55 Weinberg J, Diller L, Gordon WA, et al. Visual scanning training effect on reading-related tasks in acquired right brain damage. Arch Phys Med Rehabil 1977;58:479-86.

56 Rubens AB. Caloric stimulation and unilateral visual neglect. Neurology 1985;35:1019-24.

57 Rorsman I, Magnusson M, Johansson BB. Reduction of visuo-spatial neglect with vestibular galvanic stimulation. Scand J Rehabil Med 1999;31:117-24.

58 Schindler I, Kerkhoff G, Karnath HO, et al. Neck muscle vibration induces lasting recovery in spatial neglect. J Neurol Neurosurg Psychiatry 2002;73:412-19.

59 Wilson FC, Manly T, Coyle D, et al. The effect of contralesional limb activation training and sustained attention training for self-care programmes in unilateral spatial neglect. Restor Neurol Neurosci 2000;16:1-4.

60 Rossetti Y, Rode G, Pisella L, et al. Prism adaptation to a rightward optical deviation rehabilitates left hemispatial neglect. Nature 1998;395:166-9.

61 Frassinetti F, Angeli V, Meneghello F, et al. Long-lasting amelioration of visuospatial neglect by prism adaptation. Brain 2002;125(Pt 3):608-23.

62 Barrett AM, Goedert KM, Basso JC. Prism adaptation for spatial neglect after stroke: translational practice gaps. Nat Rev Neurol 2012;8:567-77.

63 Turton AJ, O’Leary K, Gabb J, et al. A single blinded randomised controlled pilot trial of prism adaptation for improving self-care in stroke patients with neglect. Neuropsychol Rehabil 2010;20:180-96.

64 Serino A, Barbiani M, Rinaldesi ML, et al. Effectiveness of prism adaptation in neglect rehabilitation: a controlled trial study. Stroke2009;40:1392-8.
65 Nys GM, de Haan EH, Kunneman A, et al. Acute neglect rehabilitation using repetitive prism adaptation: a randomized placebo-controlled trial. Restor Neurol Neurosci 2008;26:1-12.

66 Hesse MD, Sparing R, Fink GR. Ameliorating spatial neglect with non-invasive brain stimulation: from pathophysiological concepts to novel treatment strategies. Neuropsychol Rehabil 2011;21:676-702.

67 Koch G, Bonni S, Giacobbe V, et al. Theta-burst stimulation of the left hemisphere accelerates recovery of hemispatial neglect. Neurology 2012;78:24-30.

68 Cazzoli D, Muri RM, Schumacher R, et al. Theta burst stimulation reduces disability during the activities of daily living in spatial neglect. Brain 2012;135(Pt 11):3426-39.

69 Robertson IH, Mattingley JB, Rorden C, et al. Phasic alerting of neglect patients overcomes their spatial deficit in visual awareness. Nature 1998;395:169-72.

70 Malhotra PA, Parton AD, Greenwood R, et al. Noradrenergic modulation of space exploration in visual neglect. Ann Neurol 2006;59:186-90.

71 Apicella P, Legallet E, Nieoullon A, et al. Neglect of contralateral visual stimuli in monkeys with unilateral striatal dopamine depletion. Behav Brain Res 1991;46:187-95.

72 Carli M, Jones GH, Robbins TW. Effects of unilateral dorsal and ventral striatal dopamine depletion on visual neglect in the rat: a neural and behavioural analysis. Neuroscience 1989;29:309-27.

73 Fleet WS, Valenstein E, Watson RT, et al. Dopamine agonist therapy for neglect in humans. Neurology 1987;37:1765-70.

74 Barrett AM, Crucian GP, Schwartz RL, et al. Adverse effect of dopamine agonist therapy in a patient with motor-intentional neglect. Arch Phys Med Rehabil 1999;80:600-3.

75 Gorgoraptis N, Mah YH, Machner B, et al. The effects of the dopamine agonist rotigotine on hemispatial neglect following stroke. Brain 2012;135(Pt 8):2478-91.

76 Russell C, Li K, Malhotra PA. Harnessing motivation to alleviate neglect. Front Hum Neurosci 2013;7:230.

77 Mesulam MM. Principles of behavioral neurology. Philadelphia: F.A. Davis, 1985.

78 Malhotra PA, Soto D, Li K, et al. Reward modulates spatial neglect. J Neurol Neurosurg Psychiatry 2013;84:366-9.

79 Ishiai S, Sugishita M, Odajima N, et al. Improvement of unilateral spatial neglect with numbering. Neurology 1990;40:1395-8.

80 Soto D, Funes MJ, Guzman-Garcia A, et al. Pleasant music overcomes the loss of awareness in patients with visual neglect. Proc Natl Acad Sci U S A 2009;106:6011-16.

81 Bodak R, Malhotra P, Bernardi NF, et al. Reducing chronic visuo-spatial neglect following right hemisphere stroke through instrument playing. Front Hum Neurosci 2014;8:413.

82 Salimpoor VN, Benovoy M, Larcher K, et al. Anatomically distinct dopamine release during anticipation and experience of peak emotion to music. Nat Neurosci 2011;14:257-62.

83 Schultz W, Apicella P, Ljungberg T. Responses of monkey dopamine neurons to reward and conditioned stimuli during successive steps of learning a delayed response task. J Neurosci 1993;13:900-13. 